\title{
NOTAS
}

\section{Assessoria de Organização e Métodos nos Municipios}

JoÃo JORGE DA CUNHA

$\mathrm{U}$

MA Assessoria de Organização e Métodos dedicada aos municípios teria as atribuições de:

a) organizar Escritórios Técnicos de Planejamento Local Integrado;

b) promover a formação de Recursos Humanos para os Escritórios Técnicos de Planejamento Local Integrado.

Os trabalhos da Assessoria de Organização e Métodos interessam a todos os municipios brasileiros, pois de acôrdo com o Decreto $n^{\circ}$ 59.917, de 30-12-66, que regulamentou o Serviço Federal de Habitação e Urbanismo - SERFHAU e criou o Fundo de Financiamento de Planos de Desenvolvimento Local Integrado, "para serem beneficiárias do Fundo, as regiōes e municipalidades se obrigam a criar órgãos permanentes de planejamento e desenvolvimento local". (Art. 23). O mesmo decreto estabelece no seu artigo $5^{\circ}$, letra $\ell$ : São atribuições do SERFHAU... f) promoção de treinamento de pessoal técnico especializado, para o implemento do sistema nacional de desenvolvimento local integrado.

Os trabalhos da Assessoria de Organização e Métodos deverão interessar, também, às entidades públicas nacionais e regionais, assim como às entidades privadas que realizam planos, projetos e programas de desenvolvimento local integrado.

A fim de alcançar seus objetivos a Assessoria de Organização e Métodos deve manter a seguinte estrutura:

a) Divisão de Organização:

1 - Departamento de Relações com os Municipios, $\mathrm{RM}$; 
2 - Departamento de Análise, AN;

3 - Departamento de Organização, OR.

b) Divisão de Treinamento:

1 - Departamento de Planejamento Econômico, EC;

2 - Departamento de Planejamento Social, SO;

3 - Departamento de Planejamento Físico-Territorial, FT:

4 - Departamento de Planejamento Administrativo, AD.

\section{DIVISÃO DE ORGANIZAÇÃO}

Os trabalhos dessa Divisão obedeceriam à seguinte sistemática:

1) Departamento de RM - Os agentes de RM devem visitar os municípios, oferecendo os serviços da Assessoria e obter os acôrdos de análise à luz de argumentos convincentes.

Os agentes de RM serão profissionais de nivel universitário, de preferência, e de reconhecida capacidade no trato dos problemas municipais. Além disso, devem conhecer em detalhes o Manual de Financiamento do SERFHAU e as instruções preparadas pela Assessoria.

2) Departamento de AN - Se o trabalho de RM fôr bem feito, o analista não encontrará nenhuma dificuldade em realizar a análise, segundo as instruções do Manual. Com sua experiência, seu talento e sua honestidade, o analista deverá obter um contrato de Organização e Treinamento.

3) Departamento de Organização - Assinado o contrato de Organização e Treinamento, cabe ao Departamento de Organização, com base nas informações da análise, tomar as providências para a instalação do Escritório de Planejamentto Local Integrado. Os especialistas que trabalham na organização dos Escritórios são técnicos especializados nos vários setores do planejamento integrado assessorados por especialistas em organização.

O Departamento de Organização deverá providenciar os documentos necessários à obtenção de financiamento, de acôrdo com as instruções do Manual de Financiamento do SERFHAU.

\section{DIVISÃO DE TREINAMENTO}

Os departamentos dessa Divisão atuam com pessoal especializado, em atividades nas universidades e nas entidades públicas e privadas que atuam no campo do planejamento urbano. 
O Departamento de Organização procederá à seleção dos especialistas que atuam nos vários setores do planejamento integrado, de acôrdo com as conveniências dos municípios.

O treinamento de técnicos para os Escritórios de Planejamento Local Integrado poderá ser feito, também, por uma das entidades públicas ou privadas de cujos objetivos constem programas de treinamento de pessoal para o planejamento local integrado.

O módulo de cada Escritório de Planejamento Local Integrado é constituído de 4 especialistas, sendo 1 Economista, $1 \mathrm{Ar}$ quiteto, 1 Técnico de Administração Pública e 1 Licenciado em Ciências Sociais. Haverá possibilidades, entretanto, de colaboração de outros profissionais (sanitaristas, educadores, etc.) em programas de maior amplitude, de acôrdo com as possibilidades do município. cipios:

Os cursos de treinamento devem obedecer aos seguintes prin-

a) os programas serão interdisciplinares, com base em trabalhos de equipe;

b) os trabalhos práticos constarão de pesquisa e diagnóstico das regiões-programa na primeira etapa e de Planos Preliminares das mesmas regiões na segunda etapa;

c) as aulas teóricas terão por objetivo dar a cada técnico setorial uma visão geral sôbre os demais setores do planejamento;

d) o aprimoramento setorial do técnico será feito através de sua participação nos trabalhos práticos orientados por especialistas.

\section{TRABALHOS DE ANÁLISE}

Os analistas devem obter as seguintes informações básicas:

1 - Definição da área a ser planejada:

1.1 - Municípios(s) abrangido(s) pelo plano;

1.2 - Cidade(s) ou vila(s) abrangidas pelo plano;

1.3 - Área total;

1.4 - Área urbana, área rural;

1.5 - População urbana, população rural;

1.6 - Outros aspectos demográficos.

Indicar a fonte e o ano de referência. No caso de estimativa, indicar como foi feito o cálculo. 


\section{2 - Serviços Públicos:}

2.1 - Definir, de modo geral, a situação da área quanto aos serviços:

2.11 - de abastecimento de água;

2.12 - de energia elétrica e gás;

2.13 - de esgotos;

2.14 - de transporte coletivo;

2.15 - de comunicações;

2.16 - de educação;

2.17 - de cultura;

2.18 - de habitação (domicilios urbanos e rurais);

2.19 - de saúde.

2.2 - Projeção de gastos nos serviços públicos municipais, usando a fórmula $\mathrm{G}^{i}=\mathrm{P}_{\mathrm{i}}+\mathrm{A}^{\mathrm{i}}+\mathrm{C}_{\mathrm{i}}$, sendo $\mathrm{G}_{\mathrm{i}}$ os gastos totais do serviço, $\mathrm{P}^{i}$ o total de gastos de prestação no ano $i, A^{\prime}$ o total de gastos realizados no ano $i$ para ampliar e melhorar a qualidade do serviço no futuro e $\mathrm{C}^{\mathrm{i}}$ o total de gastos de conservação no ano $i$.

Citar todos os estudos e projetos porventura existentes. Relacionar os dados fornecidos com as necessidades atuais e futuras do município.

3 - Dados Econômicos:

3.1 - Descrever, sucintamente, a situação da área nos seguintes setores:

3.11 - Agricultura;

3.12 - Pecuária;

3.13 - Extração mineral;

3.14 - Indústria;

3.15 - Comércio;

3.16 - Serviços;

3.17 - Sistema bancário.

3.2 - Opinar sôbre quais setores da economia são passiveis de maior desenvolvimento. Justificar.

3.3 - Dar informações sôbre as arrecadações federais e estaduais da área focalizada, nos três anos anteriores à análise. Justificar.

Anote as atividades preponderantes. Quando possivel, forneça dados sôbre o valor da produção e o número de estabelecimentos, bem como a evolução dêsses dados nos últimos anos. 
4 - Dados financeiros:

4.1 - Fornecer a previsão orçamentária para o presente exercício, segundo o modêlo anexo - Demonstrativo da Receita e Despesa.

4.2 - Destacar, na conta 1.4 .1 , o valor correspondente à cota parte na conta 1.4.2.

4.3 - Fornecer os quadros de Demonstração de Receita e Despesa dos últimos 3 anos.

4.4 - Apresentar a previsão orçamentária para o próximo exercício.

5 - Planejamento:

5.1 - Quais os órgãos de planejamento já em funcionamento ou em instalação na área?

5.2 - Quais os programas de planejamento em execuçâo já elaborados ou em elaboração, na área?

5.3 - Existem, na região, técnicos treinados nos diversos setores do planejamento? Especificar em que setores.

5.4 - Quais os técnicos locais que poderão ser aproveitados, após treinamento com especialistas da Assessoria de Organização e Métodos.

6 - Indicadores:

6.1 - De riqueza:

6.11 - Impostos de Circulação de Mercadorias, $\mathrm{p} / \mathrm{hab}$;

6.12 - Número de veículos automotores de passeio, $\mathrm{p} / \mathrm{hab}$;

6.13 - Receita própria municipal, p/hab;

6.14 - Valor da produção animal, por habitante;

6.15 - Valor da produção agrícola, p/hab.

6.2 - De industrialização:

6.21 - Percentagem da população ativa na indústria;

6.22 - Valor da produção industrial, p/hab;

6.23 - Consumo de energia elétrica para fins industriais, $\mathrm{p} / \mathrm{hab}$;

6.24 - Técnicos de nível médio por 1.000 habitantes;

6.25 - Engenheiros por 1.000 habitantes. 
6.3 - De urbanização:

6.31 - Densidade demográfica do município (hab/ hectare);

6.32 - Percentagem da população nas áreas urbanas (situação dos últimos 5 anos).

6.33 - Migrações.

6.4 - De Educação:

6.41 - Percentagem da população total matriculada em cursos de nivel primário, médio e superior;

6.42 - Professôres de $1^{\circ}$ e $2^{\circ}$ nível por 1.000 hábitantes;

6.43 - Qualificação dos professôres;

6.44 - Dispêndios públicos em educação (União, Estado e Município - dados comparativos).

6.5 - De Saúde Pública:

6.51 - Número de médicos por 1.000 habitantes;

6.52 - Número de dentistas por 1.000 habitantes;

6.53 - Número de leitos hospitalares por 1.000 habitantes;

6.54 - Dispêndio do município com Saúde Pública em relação aos dispêndios da União e do Estado. 


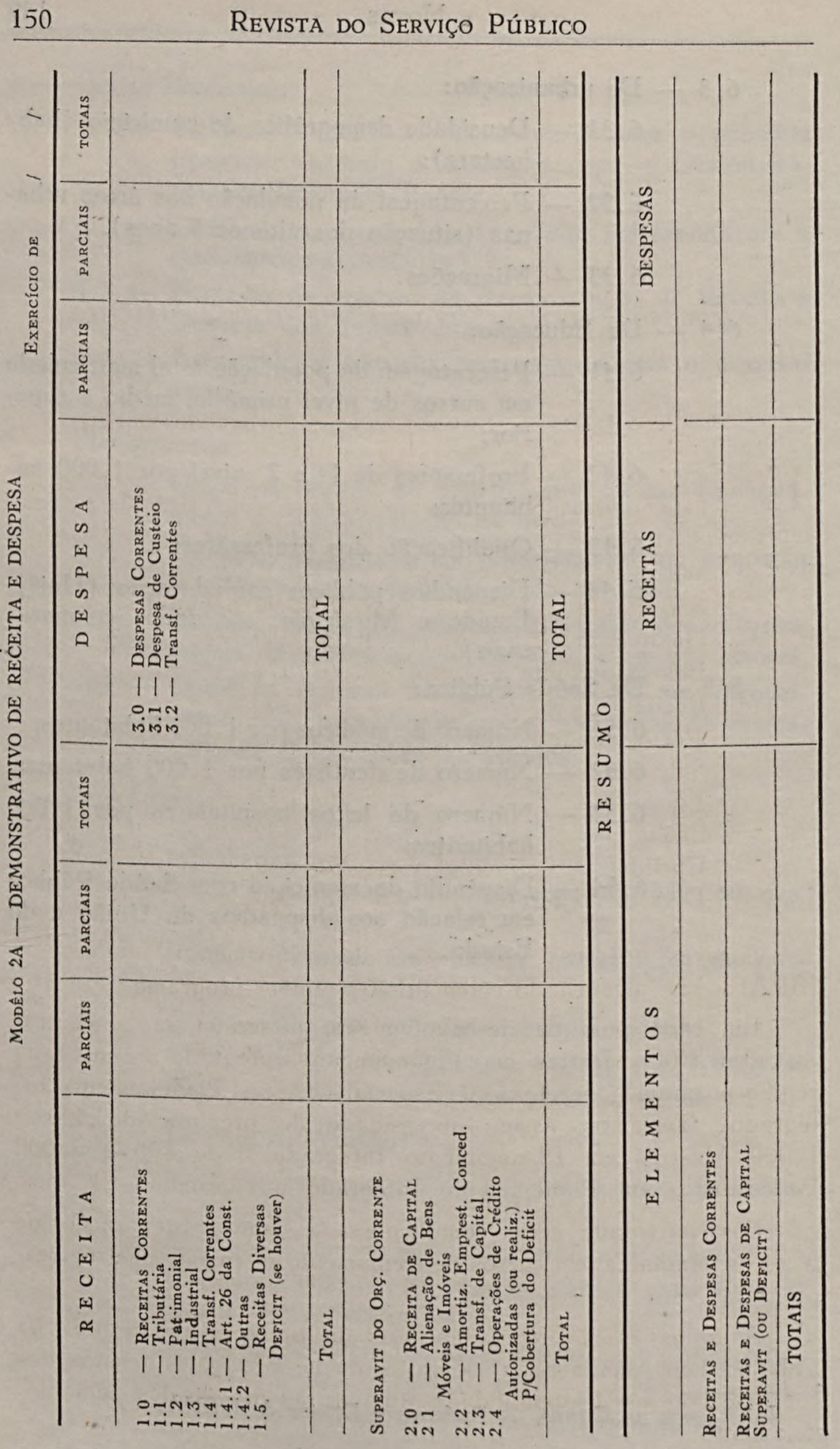

